\title{
Aryl-substituted Triarsiranes: Synthesis and Reactivity
}

\author{
André Schumann, ${ }^{a}$ Jonas Bresien, ${ }^{b}$ Malte Fischer, ${ }^{a}$ Christian Hering-Junghans ${ }^{* a}$
}

Dedicated to Prof. Dr. Uwe Rosenthal on the occasion of his 70th birthday.

[a] M.Sc. André Schumann, Dr. Malte Fischer and Dr. Christian Hering-Junghans

Leibniz Institut für Katalyse e.V. (LIKAT)

A.-Einstein-Str.3a, 18059 Rostock (Germany)

E-mail: christian.hering-junghans@catalysis.de

Website: https://www.catalysis.de/forschung/aktivierung-kleiner-molekuele/

$[\mathrm{b}] \quad \begin{gathered}\text { Dr. Jonas Bresien } \\ \text { Anorganische Chemie, Institut für Chemie } \\ \text { Universität Rostock }\end{gathered}$
A.-Einstein-Str.3a, 18059 Rostock (Germany)
Supporting information for this article is given via a link at the end of the document.

Abstract: Cyclotriarsanes are rare and limited synthetic approaches have hampered reactivity studies on these systems. Described in here is a scalable synthetic protocol towards $(\mathrm{AsAr})_{3}\left(\mathrm{Ar}=\mathrm{Dip}, 2,6-\mathrm{Pr}_{2}-\mathrm{C}_{6} \mathrm{H}_{3} ; \mathrm{Tip}, 2,4,6-{ }^{\mathrm{i}} \mathrm{Pr}_{3}-\mathrm{C}_{6} \mathrm{H}_{2}\right)$, which allowed to study their reactivity towards $\left[\mathrm{Cp}_{2} \mathrm{Ti}\left(\mathrm{C}_{2}\left(\mathrm{SiMe}_{3}\right)_{2}\right]\right.$, affording titanocene diarsene complexes and towards $\mathrm{N}$-heterocyclic carbenes (NHCs) to give straightforward access to a variety of NHC-arsinidene adducts. The electronic structure of the titanium diarsene complxes has been studied and they are best described as Ti(IV) species with a doubly reduced $\mathrm{As}_{2} \mathrm{Ar}_{2}$ ligand. These findings will make $(\mathrm{AsAr})_{3}$ valuable precursors in the synthetic inorganic and organic chemistry.

The first homoleptic cyclooligoarsane (AsPh) 6 was discovered by Michaelis and Schulte when they reduced phenyl arsenic oxide with crystalline hypophosphorous acid in refluxing ethanol, affording pale yellow crystals that were believed to be the diarsene $\mathrm{PhAs}=\mathrm{AsPh}$, the so-called arsabenzene (Scheme 1, top) ${ }^{[1]}$ Even though the synthesis and reactivity of the related cyclooligophosphanes $(P R)_{n}(n=3,4,5,6)$ has been studied in detail, ${ }^{[2]}$ the heavier oligopnictanes $(\mathrm{PnR})_{\mathrm{n}}(\mathrm{Pn}=\mathrm{As}, \mathrm{Sb}, \mathrm{Bi} ; \mathrm{n}=3,4,5,6)$ have received considerably less interest. 


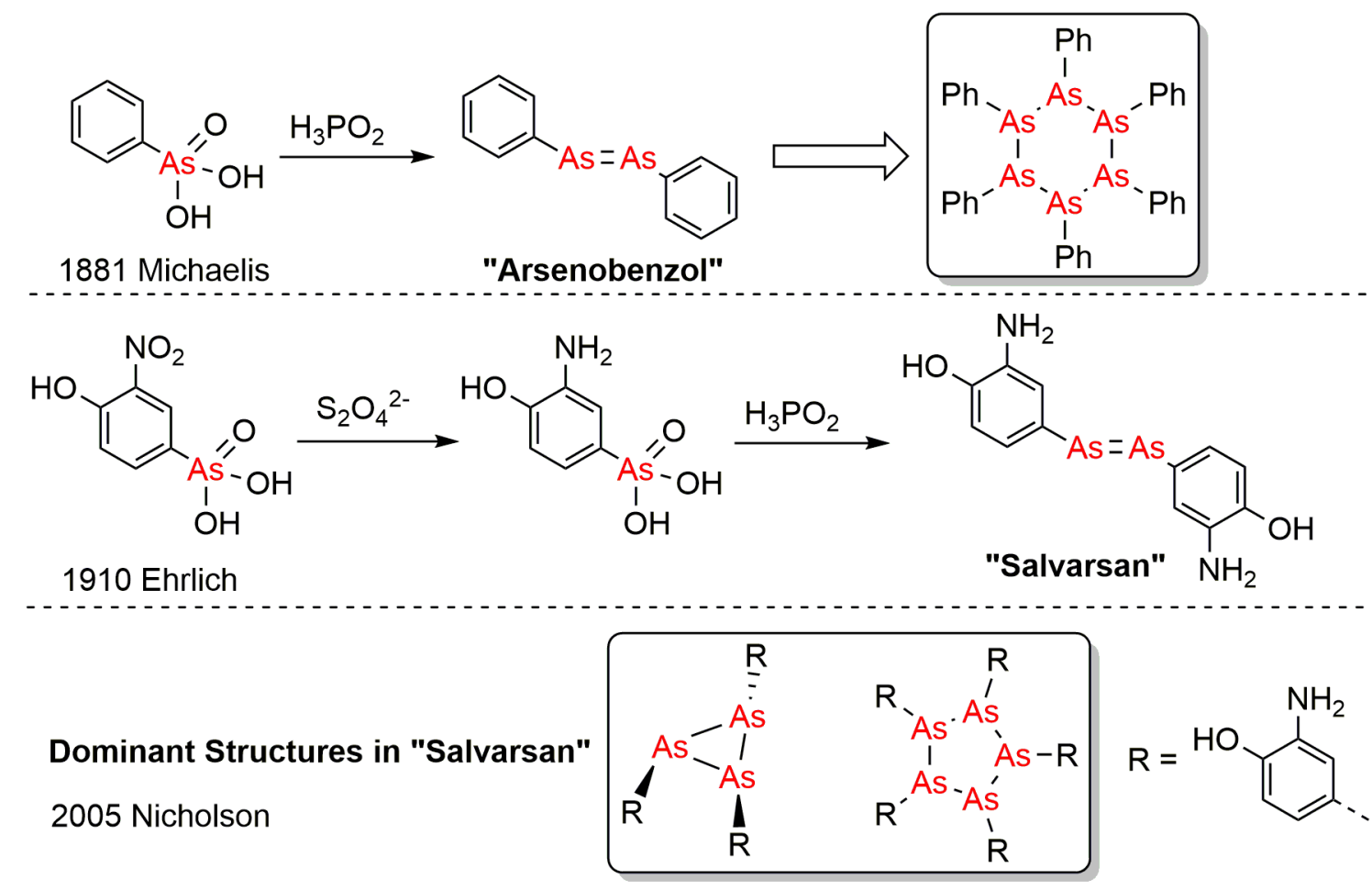

Scheme 1. Michaelis report on "Arsenobenzol", Ehrlich's "Salvarsan" and dominant structures of "Salvarsan" revealed by mass spectrometry.

To the best of our knowledge only seven examples of cyclotriarsanes, also referred to as triarsiranes, have been reported (Figure 1). In 1910 Ehrlich synthesized "Salvarsan", as a cure for syphilis, by reduction of 3-nitro-4-hydroxyphenyl-arsonic acid with dithionite and hypophosphorous acid, originally formulated as a diarsene (Scheme 1, middle). ${ }^{[3]}$ The synthesis suffered from sulfur-containing impurities, which may have accounted for the variable toxicity of salvarsan. Recently a mass spectrometric study gave the first evidence that Salvarsan mainly consists of cyclooligoarsanes $(A s R)_{n}$ $\left(\mathrm{R}=3-\mathrm{H}_{2} \mathrm{~N}-4-\mathrm{HOC}_{6} \mathrm{H}_{3 ;} \mathrm{n}=3,5 ;\right.$ Scheme 1, iii). ${ }^{[4]}$ The first cyclotriarsane derivative was 4-methyl-1,2,6-triarsatricyclo-[2.2.1.0]-heptane (Figure 1, A), a cage-compound in which the organic substituents are forced into an all-cis arrangement with respect to the $\mathrm{As}_{3}$ ring. ${ }^{[5]}$ Treatment of $\mathrm{K}_{2}\left[\mathrm{As}_{2}{ }^{\mathrm{t}} \mathrm{Bu}_{2}\right]$ with submolar amounts of ${ }^{\mathrm{t}} \mathrm{BuAsCl} \mathrm{A}_{2}$ in nonpolar solvents afforded $\left(\mathrm{As} s^{\mathrm{t}} \mathrm{Bu}\right)_{3}$ (Figure 1, B), which after tedious workup, was obtained in ca. $10 \%$ yield. ${ }^{[6]}$ In contrast, the reduction of $\mathrm{FcAsCl}_{2}$ ( $\mathrm{Fc}=$ ferrocenyl) with $\mathrm{LiAlH}_{4}$ or Zn gives $(\mathrm{AsFc})_{3}$ in almost quantitative yield (Figure 1, C). ${ }^{[7]} 1992$ West and co-workers described a rather exotic example of a cyclotriarsane within an tricyclic structure (Figure 
1, D), which was synthesized by activation of $\mathrm{As}_{4}$ with the disilene $\mathrm{Si}_{2} \mathrm{Mes}_{4}{ }^{[8]}$ In addition, a metal-carbine-substituted triarsirane $\left[\mathrm{Tp}^{*}(\mathrm{CO})_{2} \mathrm{M} \equiv \mathrm{C}-\mathrm{As}\right]_{3}\left(\mathrm{M}=\mathrm{Mo}, \mathrm{W} ; \mathrm{Tp}^{*}=\mathrm{HB}(3,5-\right.$ $\left.\mathrm{Me}_{2} \mathrm{pz}\right)_{3 ;}$ Figure 1, E) was afforded, in the cyclo-trimerization of arsanediyls of the type $\left[\mathrm{Tp}^{\star}(\mathrm{CO})_{2} \mathrm{M} \equiv \mathrm{C}-\mathrm{As}\right]{ }^{[9]}$ Recently, Kilian and co-workers constructed stable arsanylidenephosphoranes through peri-substitution of an acenaphtene-unit. ${ }^{[10]}$ Upon exposure to oxygen, the intramolecular phosphine-stabilization is removed and the free arsinidenes oligomerize to afford the respective cyclic tri- and tertraarsanes (Figure 1, F). This reactivity shows that arsanylidenephosphoranes are potential precursors for triarsiranes.

Despite their scarce representation in the literature cyclotriarsanes are interesting synthons in inorganic chemistry as evidenced by the utilization of (AsMe) ${ }_{5}$ and $(\mathrm{AsPh})_{6}$ in organoarsenic chemistry. ${ }^{[11]}$ Larger cycloarsanes $(A s R)_{n}(n=5,6)$ can not only be used as ligands, ${ }^{[12]}$ but they are also important to construct arsenic metal cluster compounds with $\mathrm{Ta}, \mathrm{Mo}, \mathrm{Ti}, \mathrm{Re}, \mathrm{W}$ and Ru. ${ }^{[13]} \mathrm{Naka}$ and co-workers showed the copolymerization of $\mathrm{As}_{5} \mathrm{Me}_{5}$ or $\mathrm{As}_{6} \mathrm{Ph}_{6}$ with monosubstituted acetylenes, ${ }^{[14]}$ in an AIBN-initiated $(\mathrm{AIBN}=$ azobis-(isobutyronitrile) $)$ radical polymerization obtaining various poly(vinylene-arsanes). The reaction of $\left(\mathrm{As}\left(\mathrm{CF}_{3}\right)_{4}\right.$ and $\left[\mathrm{Pd}\left(\mathrm{PPh}_{3}\right)_{4}\right]$ gave the diarsene complex $\left[\left(\mathrm{Ph}_{3} \mathrm{P}\right)_{2} \mathrm{Pd}\left(\mathrm{As}_{2}\left(\mathrm{CF}_{3}\right)_{2}\right)\right]$ indicating a diarsene intermediate. ${ }^{[15]} \mathrm{A}$ range of arsafluorenes, dibenzoarsepines and arsoles have been synthesized by in situ formation of RAsl $I_{2}$ from reaction of $(A s R)_{n}$ with $I_{2}$ and subsequent treatment with metalated precursor molecules. ${ }^{[16]}$ Recently we outlined a methodology for the selective synthesis of aryl substituted triphosphiranes $(\mathrm{PAr})_{3}\left(\mathrm{Ar}=\mathrm{Mes}=2,4,6-\mathrm{Me}_{3}-\mathrm{C}_{6} \mathrm{H}_{2} ; \mathrm{Dip}=2,6-{ }^{\mathrm{i}} \mathrm{Pr}_{2}-\right.$ $\mathrm{C}_{6} \mathrm{H}_{3}$, Tip $=2,4,6-\mathrm{Pr}_{3}-\mathrm{C}_{6} \mathrm{H}_{2}$ ) and their fragmentation was observed in the reaction with the masked titanocene $\left[\mathrm{Cp}_{2} \mathrm{Ti}_{(}\left(\mathrm{C}_{2}\left(\mathrm{SiMe}_{3}\right)_{2}\right]\right.$ to give titanocene diphosphene complexes selectively. ${ }^{[17]}$ 
<smiles>CC12CC3[As][As](C[As]3S1)C2</smiles>

A

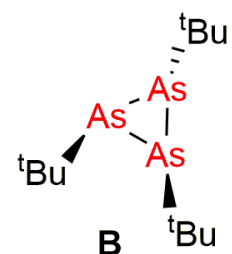

B ${ }^{t} \mathrm{Bu}$

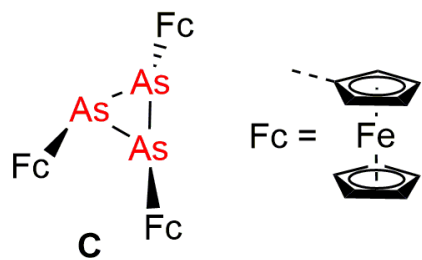

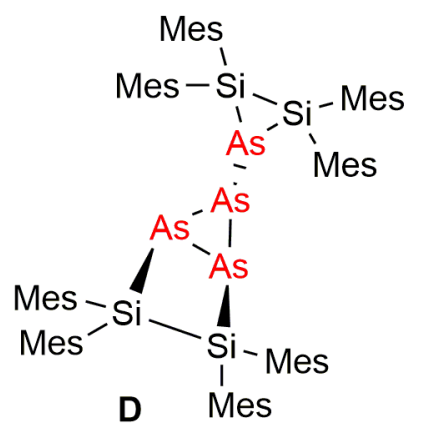
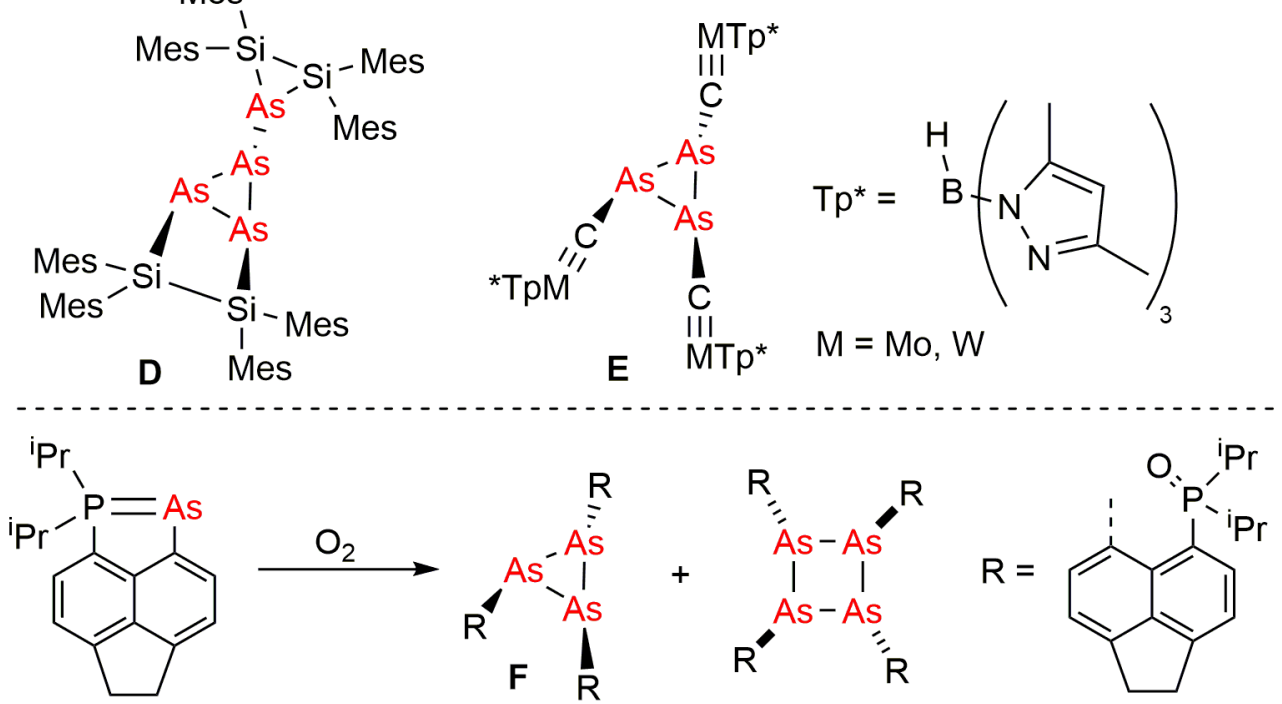

Figure 1. Cyclotriarsanes reported in the literature A-F.

In this context, we wanted to extend this concept to the analogous arsenic systems. Herein we report on the synthesis of novel cyclotriarsanes and discuss their reactivity towards $\left[\mathrm{Cp}_{2} \mathrm{Ti}\left(\mathrm{C}_{2}\left(\mathrm{SiMe}_{3}\right)_{2}\right]\right.$, giving the first examples of titanocene diarsene complexes and towards $\mathrm{N}$-heterocyclic carbenes (NHCs).

$\operatorname{TipAsCl} 2$ (1a) was obtained in a 2-step synthesis from $\mathrm{TipMgBr}$ and $\mathrm{AsCl}_{3}$ to generate the mixed dihaloarsane TipAs $\mathrm{X}_{2}$ (with $\mathrm{X}=\mathrm{Cl}, \mathrm{Br}$ ). ${ }^{[18]}$ Stirring TipAs $\mathrm{X}_{2}$ with an excess of $\mathrm{ZnCl}_{2}$ in $\mathrm{THF}$, gave TipAsCl 2 as an analytically pure, highly viscous oil in $71 \%$ yield. Attempts to similarly synthesize $\operatorname{DipAsCl}{ }_{2}$ gave a product mixture, which could not be separated. Pure DipAsCl 2 (1 b) was obtained by using Dip $2 \mathrm{Mg}$ (obtained from $\mathrm{DipMgBr}$ and an excess of 1,4-dioxane) in the transmetalation with two equivalents $\mathrm{AsCl}_{3 .}{ }^{[19]} \mathrm{In}$ a next step $\mathbf{1} \mathbf{a}$ and $\mathbf{1} \mathbf{b}$ were reduced using a mixture of $\mathrm{PMe}_{3}$ and $\mathrm{Zn}$ powder in THF at ambient temperature and after removal of the solvent, extraction of the residue with $n$-hexane and concentration to incipient crystallization, the cyclotriarsanes (AsTip) 3 (2a) and (AsDip) ${ }_{3}(\mathbf{2 b})$ were obtained as colorless crystalline solids in $65 \%$ and $79 \%$ yield, respectively (Scheme 2 ). 


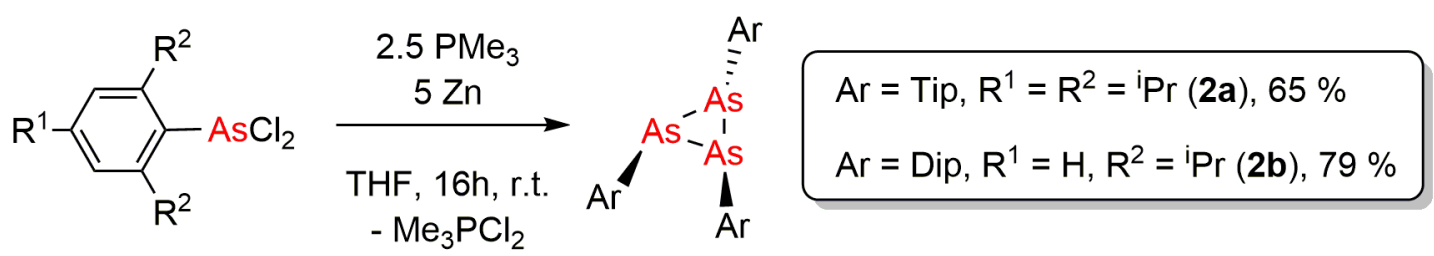

Scheme 2. Synthesis of the triarsiranes $\mathbf{2 a}$ and $\mathbf{2} \mathbf{b}$.

The ${ }^{1} \mathrm{H}$ NMR spectra of $\mathbf{2} \mathbf{a}$ and $\mathbf{2} \mathbf{b}$ each show two sets of signals for two chemically inequivalent Tip and Dip substituents, with relative intensities of 1:2, clearly indicating a cis,trans,trans-arrangement of the aryl groups with respect to the $\mathrm{As}_{3}$ ring system. No reduction of 1 was observed when using $\mathrm{Zn}$ powder in $\mathrm{THF}$, indicating that $\mathrm{PMe}_{3}$ is the active reductant. ${ }^{[17]}$ Using $\mathrm{Mg}$ turnings as a reductant, the full consumption of either $\mathbf{1} \mathbf{a}$ or $\mathbf{1} \mathbf{b}$ was detected, however, selective formation of $\mathbf{2}$ was not achieved.

$\mathbf{2 a}$ (Figure 2, left) crystallizes in the triclinic space group $P-1$ and $\mathbf{2 b}$ (Figure 2, right) in the monoclinic spacegroup $P 2_{1} / c$ with two and four molecules in the unit cell, respectively. Both $\mathbf{2 a}$ and $\mathbf{2} \mathbf{b}$ show the expected cis,trans,trans-configuration of the substituents with respect to the central, minimally distorted $\mathrm{As}_{3}$ ring, in which one of the As-As bonds [2a As2-As3 2.4767(2) A; $\mathbf{2}$ b As1-As3 2.4769(15) $\AA$ ] is significantly longer than the other two [2a 2.4514(2), 2.4530(2) $\AA$; $\mathbf{2 b}$ 2.4463(2), 2.4554(2) $\AA]$. The observed bond lengths are longer than expected for As-As single bonds $\left[\Sigma r_{\text {cov }}(\right.$ As-As $\left.)=2.42 \AA\right]{ }^{[20]}$ but in line with the three crystallographically characterized cyclotriarsanes [cf. Figure 1, F 2.4388(8), 2.472(1), 2.502(1) Å]..$^{10]}$

Complexes of titanium with arsenic ligands are rare, and titanium complexes with a coordinated diarsene ligand have not been reported to date. Reactivity studies on triarsanes are limited to few examples. $(\mathrm{AsFc})_{3}$ was shown to react with $\left[\left(\mathrm{PPh}_{3}\right)_{2} \mathrm{Pt}\left(\mathrm{C}_{2} \mathrm{H}_{4}\right)\right]$ in a 2:3 ratio to afford the diarsene-complex $\left[\left(\mathrm{PPh}_{3}\right)_{2} \mathrm{Pt}\left(\mathrm{As}_{2} \mathrm{FC}_{2}\right)\right]$. This is similar to what our group observed when $(\mathrm{PAr})_{3}$ was reacted with $\left[\mathrm{Cp}_{2} \mathrm{Ti}\left(\mathrm{C}_{2}\left(\mathrm{SiMe}_{3}\right)_{2}\right]\right.$ in a 2:3 ratio, affording titanocene diphosphoshene complexes. ${ }^{[17]}$ In $\left[\mathrm{Cp}_{2} \mathrm{Ti}(\mathrm{btmsa})\right]$ (btmsa $\left.=\mathrm{C}_{2}\left(\mathrm{SiMe}_{3}\right)_{2}\right)$ btmsa acts as a spectator ligand and its facile release under the respective reaction conditions generates the highly reactive 14 -electron $\left[\mathrm{Cp}_{2} \mathrm{Ti}\right]$ fragment in situ. ${ }^{[21]}$ 

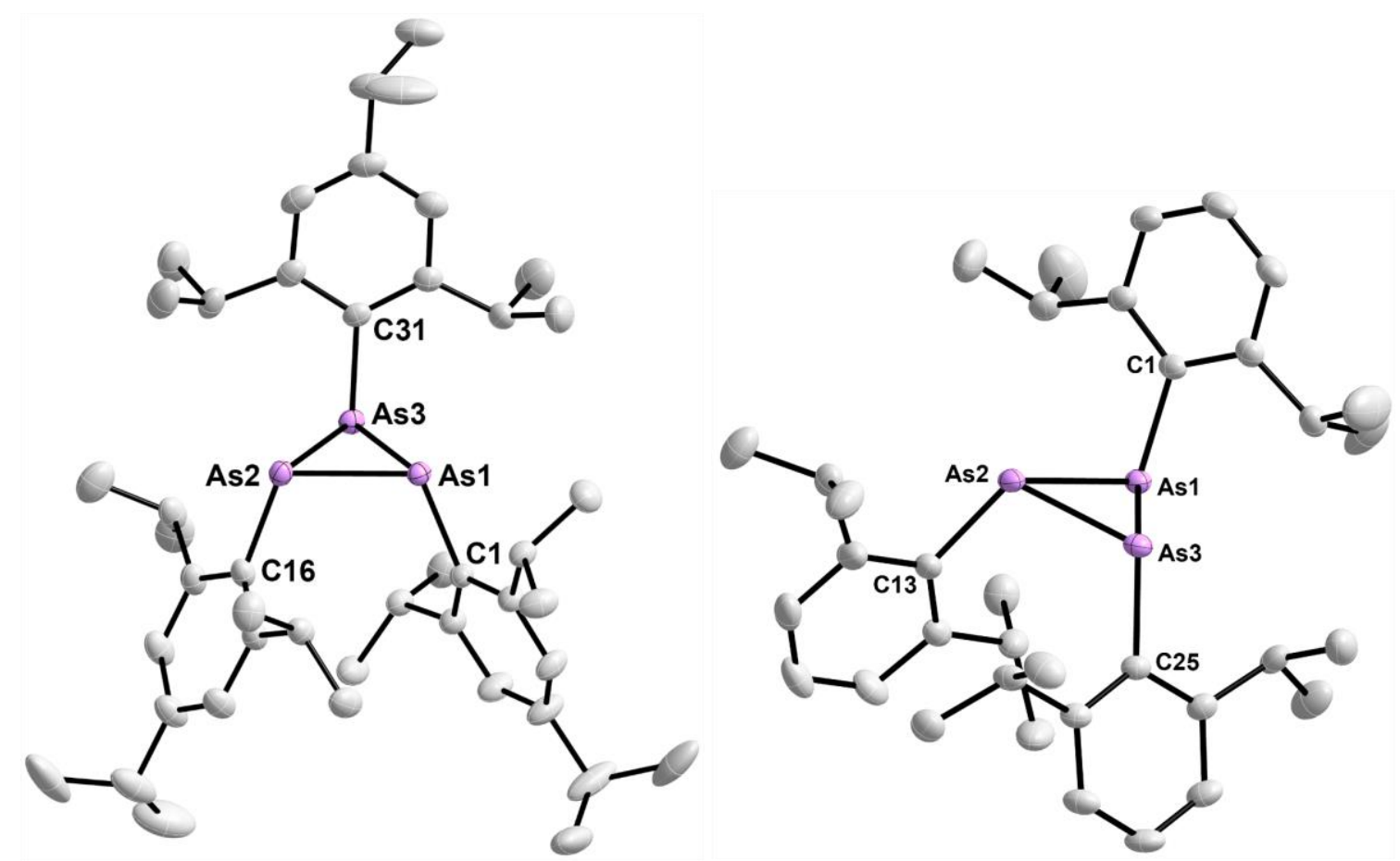

Figure 2. ORTEP drawing of the molecular structures of $\mathbf{2 a}$ and $\mathbf{2 b}$. Ellipsoids drawn at $50 \%$ probability at $150(2) \mathrm{K} .{ }^{[22]} \mathrm{Hydrogen}$ atoms have been omitted for clarity. Selected bond lengths $(\AA \AA)$ and angles ( ${ }^{\circ}$ : 2a As1-As2 2.4514(2), As2-As3 2.4767(2), As1-As3 2.4530(2), As1-C1 1.9845(14), As1-C16 1.9819(5), As3-C31 1.9926(15), As1-As2-As3 59.664(6), As2-As1-As3 60.609(7), As1-As3-As2 59.727(7); 2b As1-As2 2.4463(2), As2-As3 2.4554(2), As1-As3 2.4769(15), As1-C1 1.9949(15), As2-C13 1.9831(16), As3-C25 1.9849(15), As1-As2-As3 60.705(6), As2-As1-As3 59.831(6), As1-As3-As2 59.464(6).

When $2 \mathbf{a}$ was combined with $\left[\mathrm{Cp}_{2} \mathrm{Ti}\left(\mathrm{C}_{2}\left(\mathrm{SiMe}_{3}\right)_{2}\right]\right.$ in a 2:3 ratio in $\mathrm{C}_{6} \mathrm{D}_{6}$ and the mixture was heated to $80^{\circ} \mathrm{C}$ for $16 \mathrm{~h}$ the clean formation of a new species with a set of three septets and six doublets in a 1:1:1 ratio was detected in the ${ }^{1} \mathrm{H}$ NMR spectrum (Scheme 3 , top). One of the septets is considerably shielded, which is in analogy to $\left[\mathrm{Cp}_{2} \mathrm{Ti}\left(\mathrm{P}_{2} \mathrm{Tip}_{2}\right)\right]$, and is indicative of close proximity of this proton to the $\mathrm{Cp}$ rings of $C p_{2} \mathrm{Ti}$. Dark red X-ray quality crystals of $\left[\mathrm{Cp}_{2} \mathrm{Ti}\left(\mathrm{As}_{2} \mathrm{Tip} \mathrm{p}_{2}\right)\right](3 \mathrm{a})$ were obtained from a saturated $n$-hexane solution at $-30{ }^{\circ} \mathrm{C}$ over a period of $24 \mathrm{~h}$ in $68 \%$ yield. In the same manner $\left.\left[\mathrm{Cp}_{2} \mathrm{Ti}_{\left(\mathrm{As}_{2} \mathrm{Dip}\right.}\right)\right]$ (3b) was obtained in $48 \%$ yield as dark red crystalline solid. UV-Vis spectroscopy revealed a broad absorption above $800 \mathrm{~nm}$, which was identified by TDDFT calculations as a LMCT-band originating from an As-As $\pi^{*}$ orbital (HOMO) to a Ti-centered d-orbital (LUMO). ${ }^{[22]}$ Additionally, 3a and $\mathbf{3} \mathbf{b}$ show a characteristic 
absorption at $560 \mathrm{~nm}$, which was identified as a HOMO-2 to LUMO transition (cf. SI p.48ff). ${ }^{[22]}$
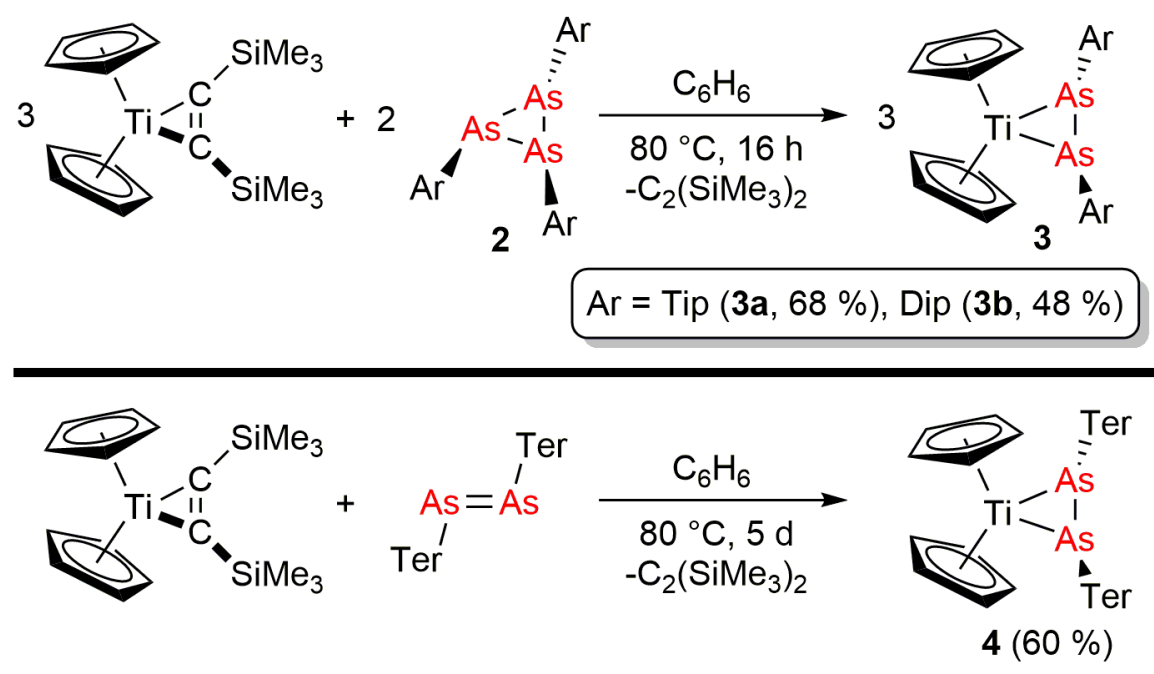

Scheme 3. Synthesis of the titanocene complexes $\mathbf{3}$ (top) and $\mathbf{4}$ (bottom).

$\mathbf{3} \mathbf{a}$ and $\mathbf{3} \mathbf{b}$ are inversion symmetric in solution as evidenced by a single resonance for the Cp groups and one set of signals for the Tip and Dip groups in the ${ }^{1} \mathrm{H}$ NMR spectrum, respectively. 3a (Figure 3, left) cyrstallizes in the orthorhombic spacegroup Pbcn on a crystallographically imposed center of inversion with half a molecule in the asymmetric unit. $\mathbf{3 b}$ (Figure 3 , right) crystallizes in the monoclinic spacegroup $P 2_{1} / n$ with one molecule in the asymmetric unit. The As-As distances in 3a [2.4877(3) $\AA$ ] and $\mathbf{3 b}[2.4572(3) \AA]$ are in the range of As-As single bonds $\left(\sum r_{\text {cov }}(\mathrm{As}-\mathrm{As})=2.42 \AA\right){ }^{[20]}$ The As-As distances in the three structurally characterized diarsene complexes $\left[\left\{\mathrm{Fe}(\mathrm{CO})_{4}\right\}\left\{\eta^{2}-\mathrm{As}_{2} \mathrm{H}_{2}\right\}\right][2.3680(5) \AA]_{1}^{[23]}\left[\mathrm{Fe}(\mathrm{CO})_{4}\left(\eta^{2}-\mathrm{C}_{6} \mathrm{~F}_{5} \mathrm{As}=\mathrm{AsC}_{6} \mathrm{~F}_{5}\right)_{2}\right][2.388(7) \AA]_{1}^{[24]}$ and $\left[\left(\mathrm{Ph}_{3} \mathrm{P}\right)_{2} \mathrm{Pd}\left(\mathrm{\eta}^{2}-\mathrm{F}_{3} \mathrm{CAs}=\mathrm{AsCF}_{3}\right)\right] \quad[2.341(1)]^{[15]}$ are considerably shorter and more representative of a diarsene complex, whereas in $\mathbf{3}$ a considerable charge transfer supposedly affords a Ti(IV) complex with a doubly reduced [ArAs-AsAr] ${ }^{2-}$ ligand. The Ti-As distances are rather short [3a 2.6255(4); 3b 2.6302(4), 2.6428(4) $\AA$ ] when

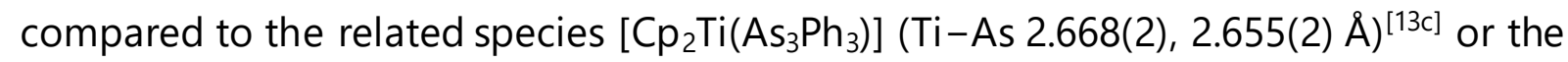
$\mathrm{Ti}(\mathrm{IV})$ complex $\left[\mathrm{Cl}_{4} \mathrm{Ti}\left(\mathrm{AsPh}_{3}\right)\right]\left(\mathrm{Ti}-\mathrm{As} 2.7465(13) \AA ̊()^{[25]}\right.$

In analogy to the synthesis of $\mathbf{2}$, the diarsene (AsTer) ${ }_{2}$ was prepared using an excess $\mathrm{PMe}_{3}$ and $\mathrm{Zn}$ in THF. This route was outlined by Protasiewicz and co-workers and was 
used to access the isolable arsanylidenephosphorane ${ }^{\text {Tip TerAsPMe }}{ }_{3}$ (Tip Ter $=2,6-$ $\mathrm{Tip}_{2} \mathrm{C}_{6} \mathrm{H}_{3}$ ), which is converted into the corresponding diarsene upon heating. ${ }^{[26]}$ Upon heating a mixture of $(A s T e r)_{2}$ with $\left[\mathrm{Cp}_{2} \mathrm{Ti}_{(}\left(\mathrm{C}_{2}\left(\mathrm{SiMe}_{3}\right)_{2}\right]\right.$ in $\mathrm{C}_{6} \mathrm{D}_{6}$ for 5 days (Scheme 3, bottom), clean conversion into a new species showing one signal for the $\mathrm{Cp}$-protons and six signals in a 1:1:1:1:1:1 ratio for the methyl groups of the ortho-mesityl groups of the terphenyl moiety in the

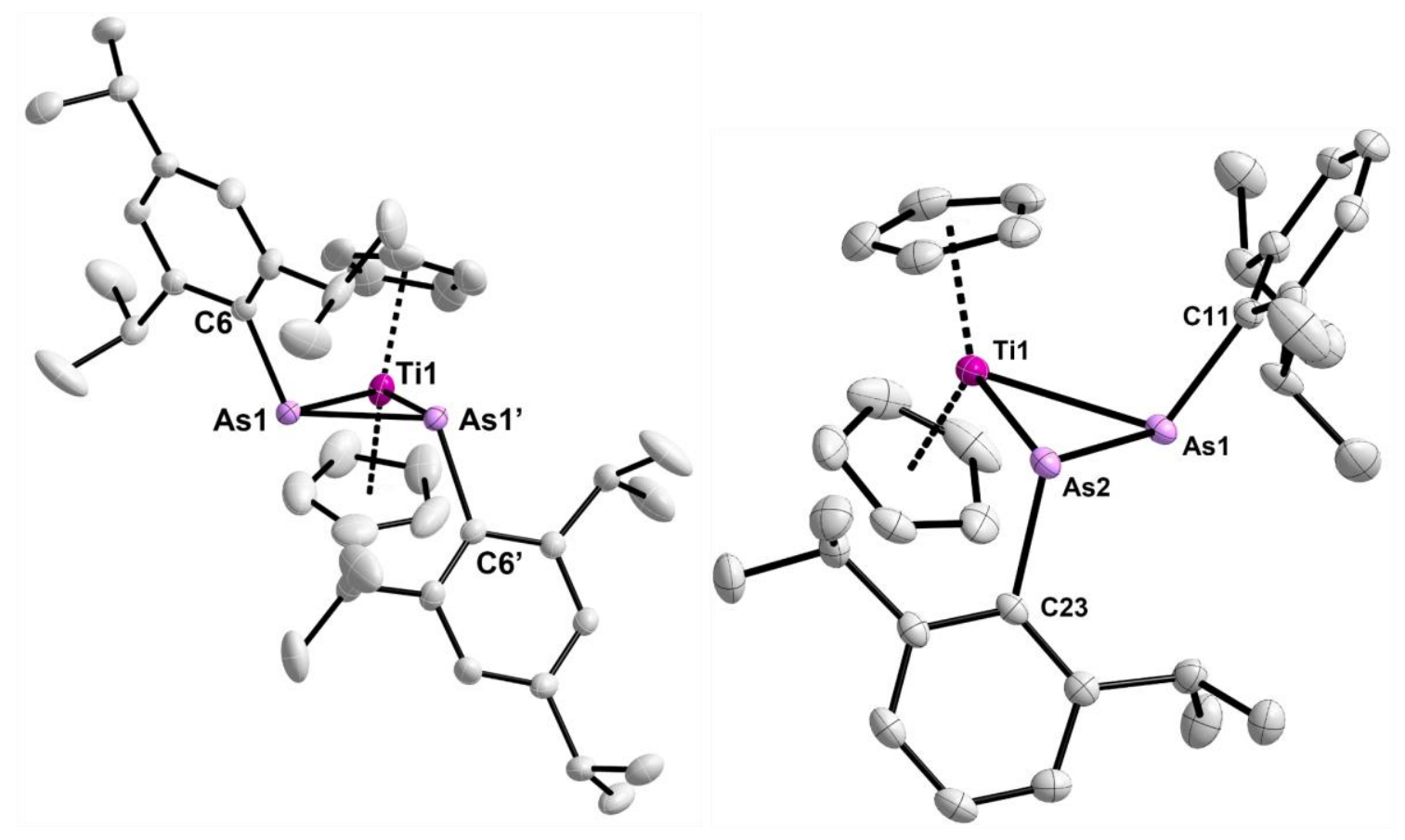

Figure 3. ORTEP drawing of the molecular structures of $\mathbf{3} \mathbf{a}$ and $\mathbf{3 b}$. Ellipsoids drawn at $50 \%$ probability at 150(2) K. Hydrogen atoms have been omitted for clarity. Selected bond lengths $(\AA)$ and angles ( ${ }^{\circ}$ ): $3 \mathbf{a}$ As1-As1' 2.4877(3), Ti1-As1 2.6255(4), As1-C6 1.9982(14); As1-Ti1-As1' 56.558(11), Ti1-As1-As1' 61.721(6), Ti1-As1-C6 110.53(4), As1'-As1-C6 110.86(4); 3b As1-As2 2.4572(3), Ti1-As1 2.6302(4), Ti1-As2 2.6428(4), As1-C11 1.9968(16), As2-C23 1.9914(17); As1-Ti1-As2 55.549(10), Ti1-As1-As2 61.964(11), Ti1-As2-As1 62.487(9), Ti1-As1-C11 110.32(5), Ti1-As2-C23 114.35(5), As2-As1-C11 107.93(5), As1-As2-C23 107.93(5) 110.73(5).

${ }^{1} \mathrm{H}$ NMR spectrum. X-Ray quality crystals were obtained by slow evaporation of the $\mathrm{C}_{6} \mathrm{D}_{6}$ solution and confirmed the formation of the diarsene complex $\left[\mathrm{Cp}_{2} \mathrm{Ti}_{(}\left(\mathrm{As}_{2} \mathrm{Ter}_{2}\right)\right](4)$ as a $C_{6} D_{6}$ solvate (Figure 4). The As-As distance in 4 [2.4440(3) $\AA$ ] is in the range of complexes 3 and considerably longer then in free (AsTer) $2[2.276(3) \AA]_{1}^{[27]}$ and thus more descriptive of an As-As single bond. The As-Ti-As angle [4 54.738(11) ${ }^{\circ}$ ] is narrower than in $\mathbf{3 a}\left[56.558(11)^{\circ}\right]$ and $\mathbf{3 b}$ [55.549(10) $\left.{ }^{\circ}\right]$, while the $\mathrm{Ti}-\mathrm{As}$ distances are 
minimally longer [4 2.6581(5), 2.6582(5) $\AA]$, in line with the decreased As-As distance in 4. The terphenyl groups are in a trans arrangement and from the molecular structure the hindered rotation about the As-C axis is evident, explaining the six inequivalent methyl groups in the ${ }^{1} \mathrm{H}$ NMR spectrum. The formation of $\mathbf{4}$ shows that diarsenes are potential intermediates in the formation of $\mathbf{3} \mathbf{a}$ and $\mathbf{3} \mathbf{b}$.

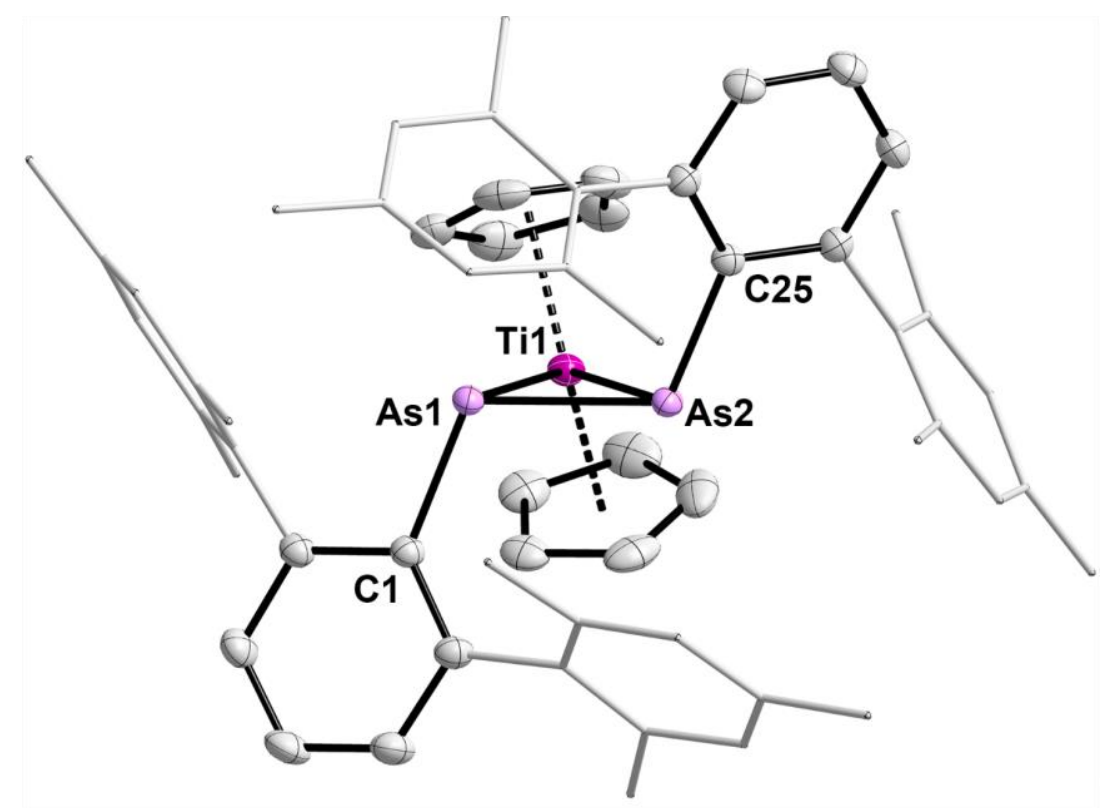

Figure 4. ORTEP drawing of the molecular structures of 4. Ellipsoids drawn at $50 \%$ probability at $150(2) \mathrm{K}$. Hydrogen atoms have been omitted for clarity. Selected bond lengths $(\AA)$ and angles $\left(^{\circ}\right)$ : As $1-$ As2 2.4440(3), Ti1-As1 2.6581(5), Ti1-As2 2.6582(5), As1-C1 2.004(2), As2-C25 2.004(2); As1-Ti1-As2 54.738(11), Ti1-As1-As2 62.632(13), Ti1-As2-As1 62.630(17), Ti1-As1-C1 108.50(7), Ti1-As2-C25 109.36(7), As2-As1-C11111.41(7), As1-As2-C23 107.93(5) 111.10(7).

The electronic structures of compounds 2, 3, and $\mathbf{5}$ were investigated by Density Functional Theory (DFT) ${ }^{[28]}$ and ab-initio calculations ${ }^{[29]}$ (for a detailed description of all computations, please refer to the SI, p. S39ff). As expected, the As 3 ring systems 2 display three covalent As-As bonds; their electronic structure is primarily interesting in comparison with the Ti complexes $\mathbf{3}$ (see below, cf. Figure 5). The electronic structure of the latter was of particular interest, especially regarding the formal oxidation state of the $\mathrm{Ti}$ atom; that is, whether the complex is best described as a diarsene-Ti(II) complex, a diarsanediide-Ti(IV) complex, or possibly even a Ti(III) complex with a singly reduced diarsene ligand (and antiferromagnetic coupling between the unpaired 
electrons). To that end, Complete Active Space SCF (CASSCF) computations were performed. The active space was chosen to include the relevant bonding and antibonding $\sigma(\mathrm{As}-\mathrm{As})$ and $\pi(\mathrm{As}-\mathrm{As})$ orbitals of the ligand, which interact with the $d$ orbitals at the titanocene unit, resulting in 6 electrons in 6 orbitals, i.e. a $\operatorname{CAS}(6,6)$ calculation. Inspection of the Natural Orbitals (NOs) clearly implies that the three occupied orbitals are localized at the ligand to a significant extent (Figure 5, left). The Ti-As bonding is mainly described by orbitals $2 a$ and $7 b$, which involve the formal $\pi$ and $\pi^{*}$ orbitals of the $[\mathrm{AsR}]_{2}$ moiety.

As there is no significant static correlation between orbitals $1 b$ and $2 b$, the biradical character is low $(\beta=10 \%)$, ${ }^{[30]}$ and the complex is best described as a closed-shell Ti(IV) complex with a diarsanediide ligand. This agrees well with the observed structural parameters (see above). It is worth noting the similarities between the bonding orbitals of the $\mathrm{TiAs}_{2}$ and $\mathrm{As}_{3}$ ring system (Figure 5), underlining the description of the Ti species as a metallacycle.

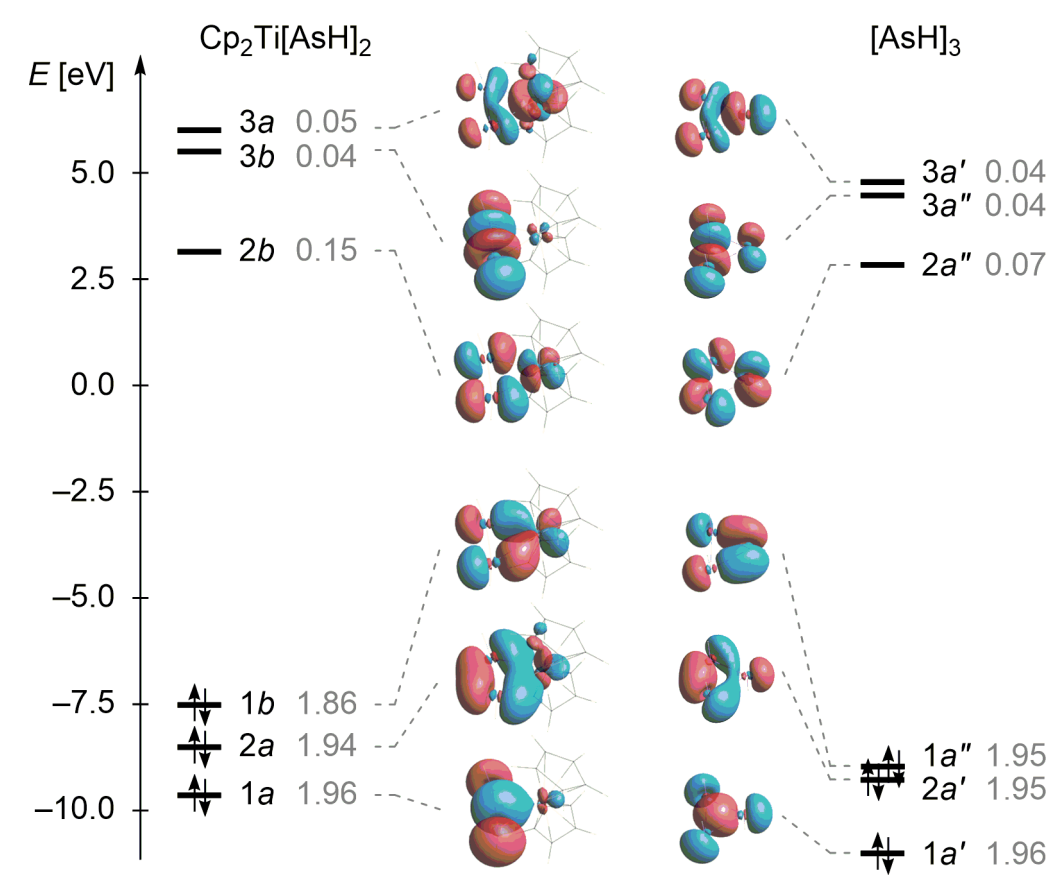

Figure 5. Depiction of the Natural Orbitals (NOs) of the active space (CAS(6,6)/def2-TZVP) of the model systems $\mathrm{Cp}_{2} \mathrm{Ti}[\mathrm{AsH}]_{2}$ (point group $\mathrm{C}_{2}$ ) and $[\mathrm{AsH}]_{3}$ (point group $\mathrm{C}_{\mathrm{S}}$ ). Results for $\mathbf{2} \mathbf{b}$ as well as $\mathbf{3} \mathbf{a}$ and $\mathbf{3} \mathbf{b}$ are essentially identical, see Figures S28, S30, S31. ${ }^{[22]}$ NO Occupation Numbers (NOONs) are given in 
grey, indicating no substantial multireference character of the wavefunctions. The weights of the depicted determinants are $89 \%$ and $93 \%$, respectively.

Complementary Natural Bond Orbital (NBO) ${ }^{[31]}$ analyses (PBE-D3/def2-TZVP level of theory) resulted in a similar picture; there are two Ti-As $\sigma$ bonds that are polarized towards the As atoms (NBO: As 62\%, Ti 38\%; see also Figures S7-S9). The Wiberg bond indices ${ }^{[31 a]}$ for both $\mathrm{Ti}-\mathrm{As}$ bonds amount to $0.87(\mathbf{3 a}, \mathbf{3 b})$, which is similar to the bond order of the As-As bond (0.85). This again points towards a formally doubly reduced diarsene moiety (Scheme 4). It is worthy to note that the lone pairs (LPs) at the two arsenic atoms do not contribute significantly to the Ti-As bonding.

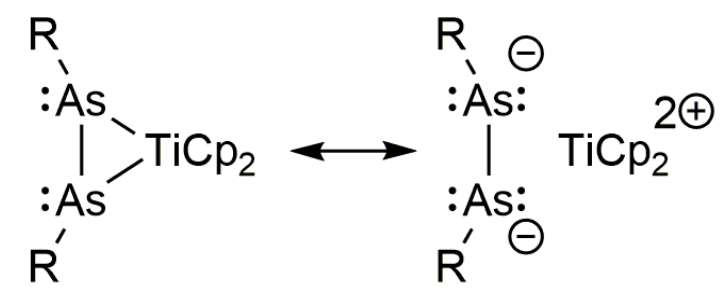

Scheme 4. Leading Lewis resonance structures of $\mathbf{3 a / 3 b .}$

$\mathrm{N}$-heterocyclic carbene-arsinidene were first reported by Arduengo et al. from the reaction of IMes (IMes = 1,3-dimesitylimidazol-2-ylidene) with $(\mathrm{AsPh})_{6}$ or $\left(\mathrm{AsC}_{6} \mathrm{~F}_{5}\right)_{4}$, respectively. ${ }^{[32]} \mathrm{X}$-ray diffraction analyses revealed structural parameters that are consistent with the notation as inversely polarized arsaalkenes. In addition, NHC adducts of the parent arsinidene "AsH" have been recently synthesized. ${ }^{[33]}$ In contrast to NHC-phosphinidene adducts, ${ }^{[34]}$ the chemistry of their analogous arsenic compounds is considerably less developed. ${ }^{[35]}$

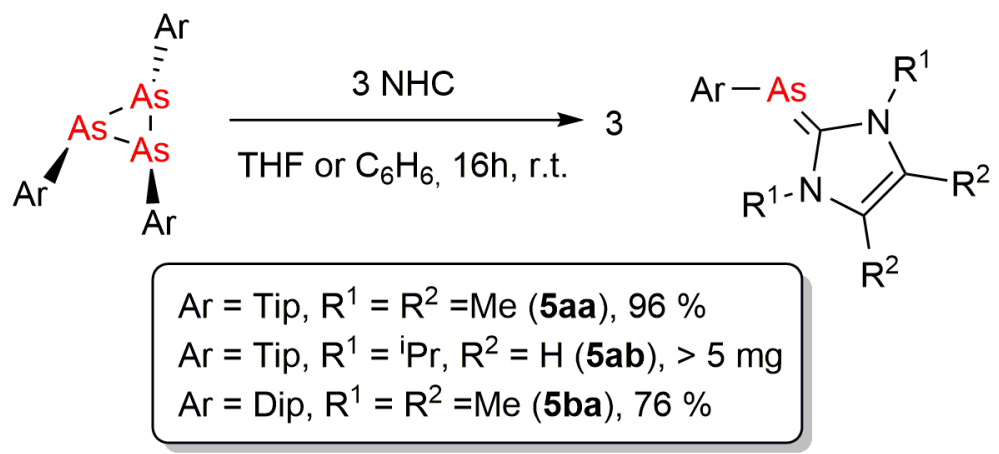


Scheme 5. Utilization of $\mathbf{3}$ for the synthesis of NHC arsinidene adducts $\mathbf{5}$.

Cyclotriarsanes 2 offer a straightforward access to a series of $\mathrm{NHC}$-arsinidene adducts by simple combination of $\mathbf{2 a}$ or $\mathbf{2} \mathbf{b}$ with the carbenes $\mathrm{IMe}_{4}\left(\mathrm{IMe}_{4}=1,3,4,5-\right.$ tetramethylimidazol-2-ylidene) or I' $\mathrm{Pr}_{2}$ (I $\mathrm{Pr}_{2}=1,3$-diisopropylimidazol-2-ylidene) in THF or benzene at room temperature and TipAs $=\operatorname{IMe}_{4}(\mathbf{5 a a}), \operatorname{TipAs}=I \mathrm{P} \operatorname{Pr}_{2}(\mathbf{5 a b})$ and DipAs $=\mathrm{IMe}_{4}$ (5 $\mathbf{b a}$ ) were obtained as yellow solids (Scheme 5). X-Ray quality crystals of $\mathbf{5} \mathbf{a a}$ and $\mathbf{5} \mathbf{a b}$ were obtained from saturated $n$-hexane or $n$-pentane solutions at $-30^{\circ} \mathrm{C}$ over a period of $24 \mathrm{~h}$, respectively (Figure 6). The As- $\mathrm{C}_{\mathrm{NHC}}$ distances [5aa 1.909(3), $5 \mathbf{a b}$ $1.9376(16) \AA]$ are minimally shorter than expected for a single bond ( $\Sigma r_{\text {cov }}$ (As$C)=1.96 \AA)$, ${ }^{[20]}$ and in agreement with the $A s-C_{N H C}$ distance in IMes=AsPh $[1.899(3) \AA]]^{[32]}$ The $\mathrm{C}-\mathrm{As}-\mathrm{C}_{\mathrm{NHC}}$ in $\mathbf{5} \mathbf{a b}\left[94.97(7)^{\circ}\right]$ is rather acute, whereas the angle for $\mathbf{5 a a}\left[104.83(12)^{\circ}\right]$ is wider, which is in line with the longer As $-C_{N H C}$ in $\mathbf{5 a b}$. Lastly, NBO analyses were performed for the NHC-arsinidene adducts $\mathbf{5}$.
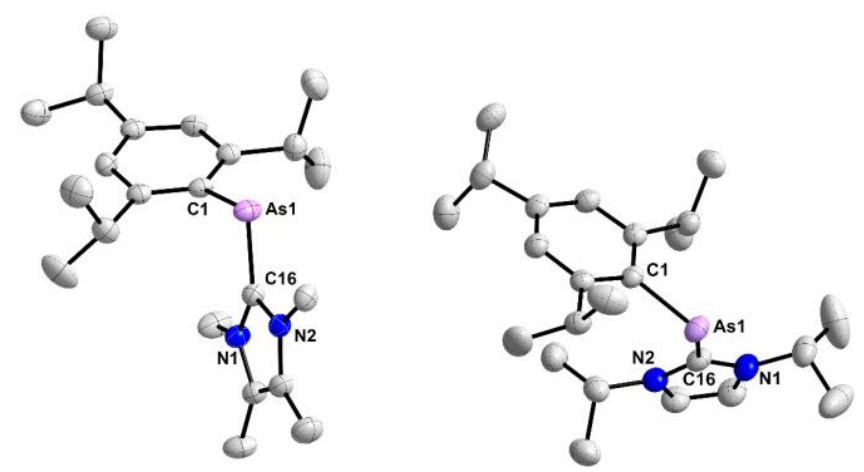

Figure 6. ORTEP drawing of the molecular structures of $\mathbf{5}$ aa and $\mathbf{5} \mathbf{a b}$. Ellipsoids drawn at $50 \%$ probability at $150(2)$ K. Hydrogen atoms have been omitted for clarity. Selected bond lengths $(\AA)$ and angles ( $\left.{ }^{\circ}\right)$ :5aa As1-C16 1.909(3), As1-C1 1.989(3), N1-C16 1.361(4), N2-C16 1.360(4); C16-As1-C1 104.83(12), N2-C16-N1 105.0(2); 5ab As1-C16 1.9376(16), As1-C1 1.9854(15), N1-C16 1.351(2), N2-C16 1.352(2); C16-As1-C1 94.97(7), N2-C16-N1 105.59(13).

In accord with a Wiberg bond index of approx. 1.2 for the $A s-C_{N H C}$ bond, a polarized As-C $\pi$ orbital is found, which is mainly localized at the As atom (5aa: As 75\%, 5ab: $67 \%$; cf. Figures S37, S38). Thus, the electronic structure is best described as an inversely polarized arsaalkene. 
In summary we have outlined a straightforward route to aryl-substituted cyclotriarsanes and have shown their utility in the formation of the first diarsene complexes 3. DFT and CASSCF calculations revealed that complexes $\mathbf{3}$ and $\mathbf{4}$ are best described as Ti(IV) complexes with a doubly reduced diarsendiide ligand. In addition, NHC arsinidene adducts $\mathbf{5}$ are conveniently prepared from the combination of $\mathbf{2}$ with NHCs. Currently studies are underway to apply the synthetic methodology described in here to uncover the structure of the active agents in Ehrlich's "Salvarsan" as well as utilizing triarsiranes as synthons for binary group 13/15 systems.

\section{Acknowledgements}

C. H.-J. thanks Prof. M. Beller for his support, the European Union for funding ( $\mathrm{H} 2020$ MSCA-IF-2017 792177), the Max Buchner-Foundation for a Scientific Fellowship and support by an Exploration Grant of the Boehringer Ingelheim Foundation (BIS) is acknowledged. We thank our technical and analytical staff for assistance, especially Dr. Anke Spannenberg for her support regarding X-ray analysis. J. B. wishes to thank the ITMZ at the University of Rostock for access to the Cluster Computer and especially Malte Willert for technical support.

\section{Conflict of Interests}

The authors declare no conflict of interest.

Keywords: Triarsiranes • Titanocenes • Electronic Structure • NHC Arsinidene adducts

- Diarsenes

\section{References}

[1] A. Michaelis, C. Schulte, Ber. Dtsch. Chem. Ges. 1881, 14, 912-914.

[2] a) I. Haiduc, The Chemistry of Inorganic Ring Systems; Wiley-Interscience: London, 1970, Part 1, 93; b) M.Baudler, Angew. Chem. Int. Ed. Engl. 1982, 21, 492-512; c) M. Baudler, K. Glinka, Chem. Rev. 1993, 93, 1623-1667; d) T. Wellnitz, C. Hering-Junghans, Eur. J. Inorg. Chem. 2020, doi: 10.1002/ejic.202000878. 
[3] a) P. Ehrlich, A. Bertheim, Ber. Dtsch. Chem. Ges. 1912, 45, 756-766; b) W. G. Christiansen, J. Am. Chem. Soc. 1921, 43, 2202-2210; c) S. Riethmiller, Bull. Hist. Chem. 1999.

[4] N. C. Lloyd, H. W. Morgan, B. K. Nicholson, R. S. Ronimus, Angew. Chem. Int. Ed. 2005, 44, 941944.

[5] G. Thiele, G. Zoubek, H. A. Lindner, J. Ellermann, Angew. Chem. Int. Ed. Engl. 1978, 17, 135-136.

[6] M. Baudler, P. Bachmann, Angew. Chem. Int. Ed. Engl. 1981, 20, 123-124.

[7] C. Spang, F. T. Edelmann, M. Noltemeyer, H. W. Roesky, Chem. Ber. 1989, 122, 1247-1254.

[8] R. P. Tan, N. M. Comerlato, D. R. Powell, R. West, Angew. Chem. Int. Ed. Engl. 1992, 31, 12171218.

[9] L. Weber, G. Dembeck, P. Lönneke, H.-G. Stammler, B. Neumann, Organometallics 2001, 20, 2288-2293.

[10] B. A. Chalmers, M. Bühl, K. S. Athukorala Arachchige, A. M. Z. Slawin, P. Kilian, J. Am. Chem. Soc. 2014, $136,6247-6250$.

[11] H. Imoto, K. Naka, Arsenic-Containing Oligomers and Polymers, In Main Group Strategies towards Functional Hybrid Materials (eds T. Baumgartner and F. Jäkle), 2018, pp. 383-403.

[12] a) R. M. De Silva, M. J. Mays, P. R. Raithby, G. A. Solan, J. Organomet. Chem.2002, 642, 237-245; b) R. M. De Silva, M. J. Mays, G. A. Solan, J. Organomet. Chem.2002, 664, 27-36.

[13] a) A. J. DiMaio, A. L. Rheingold, Organometallics 1987, 6, 1138-1139; b) A.-J. DiMaio, A. L. Rheingold, J. Chem. Soc., Chem. Commun. 1987, 404-405; c) P. Mercando, A.-J. Dimaio, A L Rheingold, Angew. Chem. 1987, 99, 252-253; d) A. L. Rheingold, M. E. Fountain, A. J. DiMaio, J. Am. Chem. Soc. 1987, 109, 141-148; e) J. R. Harper, M. E. Fountain, A. L. Rheingold, Organometallics 1989, 8, 2316-2320; f) A. J. DiMaio, T. E. Bitterwolf, A. L. Rheingold, Organometallics 1990, 9, 551-555; g) K. Mast, O. J. Scherer, G. Wolmershäuser, Z. Anorg. Allg. Chem. 1999, 625, 1475-1478.

[14] T. Umeyama, K. Naka, A. Nakahashi, Y. Chujo, Macromolecules 2004, 37, 1271-1275.

[15] J. Grobe, A. Karst, B. Krebs, M. Läge, E.-U. Würthwein, Z. Anorg. Allg. Chem. 2006, 632, 599-608.

[16] a) M. Ishidoshiro, Y. Matsumura, H. Imoto, Y. Irie, T. Kato, S. Watase, K. Matsukawa, S. Inagi, I. Tomita, K. Naka, Org. Lett. 2015, 17, 4854-4857; b) T. Kato, S. Tanaka, K. Naka, Chem. Lett 2015, 44, 1476-1478; c) H. Imoto, S. Tanaka, T. Kato, S. Watase, K. Matsukawa, T. Yumura, K. Naka, 
Organometallics 2016, 35, 364-369; d) M. Ishidoshiro, H. Imoto, S. Tanaka, K. Naka, Dalton Trans. 2016, 45, 8717-8723; e) T. Kato, H. Imoto, S. Tanaka, M. Ishidoshiro, K. Naka, Dalton Trans. 2016, 45, 11338-11345; f) H. Imoto, A. Urushizaki, I. Kawashima, K. Naka, Chem. - Eur. J. 2018, 24, 8797-8803; g) I. Kawashima, H. Imoto, M. Ishida, H. Furuta, S. Yamamoto, M. Mitsuishi, S. Tanaka, T. Fujii, K. Naka, Angew. Chem. Int. Ed. 2019, 58, 11686-11690.

[17] A. Schumann, F. Reiß, H. Jiao, J. Rabeah, J.-E. Siewert, I. Krummenacher, H. Braunschweig, C. Hering-Junghans, Chem. Sci. 2019, 10, 7859-7867.

[18] A. C. Behrle, J. R. Walensky, Dalton Transactions 2016, 45, 10042-10049.

[19] H. Klöcker, J. C. Tendyck, L. Keweloh, A. Hepp, W. Uhl, Chem. - Eur. J. 2019, 25, 4793-4807.

[20] P. Pyykkö, M. Atsumi, Chem. - Eur. J. 2009, 15, 12770-12779.

[21] T. Beweries, M. Haehnel, U. Rosenthal, Catal. Sci. \& Tech. 2013, 3, 18-28.

[22] Experimental and computational details, and details on the $X$-ray diffraction studies are included in the SI. CCDC 2041965-2041971 contain the supplementary crystallographic data for thispaper. These data are provided free of charge by the jointCambridge Crystallographic Data Centre and Fachinforma-tionszentrum Karlsruhe Access Structures service www.ccdc.cam.ac.uk/structures.

[23] R. Rund, G. Balázs, M. Bodensteiner, M. Scheer, Angew. Chem. Int. Ed. 2019, 58, 16092-16096.

[24] P. S. Elmes, P. Leverett, B. O. West, J. Chem. Soc. D: Chem. Commun. 1971, 747b-748.

[25] T. Thomas, D. Pugh, I. P. Parkin, C. J. Carmalt, Dalton Trans. 2010, 39, 5325-5331.

[26] R. C. Smith, P. Gantzel, A. L. Rheingold, J. D. Protasiewicz, Organometallics 2004, 23, 5124-5126.

[27] B. Twamley, C. D. Sofield, M. M. Olmstead, P. P. Power, J. Am. Chem. Soc. 1999, 121, 3357-3367.

[28] a) J. P. Perdew, K. Burke, M. Ernzerhof, Phys. Rev.Lett. 1996, 77, 3865-3868; b) J. P. Perdew, K. Burke, M. Ernzerhof, Phys. Rev. Lett. 1997, 78, 1396-1396; c) F. Weigend, R. Ahlrichs, Phys. Chem. Chem. Phys. 2005, 7, 3297-3305; d) F. Weigend, Phys. Chem. Chem. Phys. 2006, 8, 1057-1057; e) S. Grimme, J. Antony, S. Ehrlich, H. Krieg, J. Chem. Phys. 2010, 132, 154104; f) S. Grimme, S. Ehrlich, L. Goerigk, J. Comput. Chem. 2011, 32, 1456-1465; g) Gaussian 09, Revision E.01, M. J. Frisch, G. W. Trucks, H. B. Schlegel, G. E. Scuseria, M. A. Robb, J. R. Cheeseman, G. Scalmani, V. Barone, B. Mennucci, G. A. Petersson, H. Nakatsuji, M. Caricato, X. Li, H. P. Hratchian, A. F. Izmaylov, J. Bloino, G. Zheng, J. L. Sonnenberg, M. Hada, M. Ehara, K. Toyota, R. Fukuda, J. Hasegawa, M. Ishida, T. Nakajima, Y. Honda, O. Kitao, H. Nakai, T. Vreven, J. A. Montgomery Jr., 
J. E. Peralta, F. Ogliaro, M. Bearpark, J. J. Heyd, E. Brothers, K. N. Kudin, V. N. Staroverov, T. Keith, R. Kobayashi, J. Normand, K. Raghavachari, A. Rendell, J. C. Burant, S. S. lyengar, J. Tomasi, M. Cossi, N. Rega, J. M. Millam, M. Klene, J. E. Knox, J. B. Cross, V. Bakken, C. Adamo, J. Jaramillo, R. Gomperts, R. E. Stratmann, O. Yazyev, A. J. Austin, R. Cammi, C. Pomelli, J. W. Ochterski, R. L Martin, K. Morokuma, V. G. Zakrzewski, G. A. Voth, P. Salvador, J. J. Dannenberg, S. Dapprich, A D. Daniels, O. Farkas, J. B. Foresman, J. V. Ortiz, J. Cioslowski, D. J. Fox, Gaussian, Inc., Wallingford CT, 2013.

[29] a) D. Hegarty, M. A. Robb, Molecular Physics 1979, 38, 1795-1812; b) R. H. A. Eade, M. A. Robb, Chem. Phys. Lett. 1981, 83, 362-368; c) H. B. Schlegel, M. A. Robb, Chem. Phys. Lett. 1982, 93, 4346; d) F. Bernardi, A. Bottoni, J. J. W. McDouall, M. A. Robb, H. B. Schlegel, Faraday Symp. Chem. Soc. 1984, 19, 137-137; eP. E. M. Siegbahn, Chem. Phys. Lett. 1984, 109, 417-423; f) M. A Robb, U. Niazi, (Eds.: H. Weinstein, G. Náray-Szabó), CRC Press, Boca Raton, FL, 1990, pp. 23-55; g) M. J. Frisch, I. N. Ragazos, M. A. Robb, H. B. Schlegel, Chem. Phys. Lett. 1992, 189, 524-528; hN. Yamamoto, T. Vreven, M. A. Robb, M. J. Frisch, H. B. Schlegel, Chem. Phys. Lett. 1996, 250, 373378; i) M. Klene, M. A. Robb, M. J. Frisch, P. Celani, J. Chem. Phys. 2000, 113, 5653-5665; j) F. Neese, WIREs Comput. Mol. Sci. 2018, 8, e1327-e1327.

[30] a) L. Salem, C. Rowland, Angew. Chem. Int. Ed. Engl. 1972, 11, 92-111; b) E. Miliordos, K. Ruedenberg, S. S. Xantheas, Angew. Chem. Int. Ed. 2013, 52, 5736-5739.

[31] a) K. B. Wiberg, Tetrahedron 1968, 24, 1083-1096; b) F. Weinhold, J. E. Carpenter, (Eds.: R. Naaman, Z. Vager), Springer, Boston, MA, 1988, pp.227-236; c) F. Weinhold, C. R. Landis, Valency and Bonding. A Natural Bond Orbital Donor-Acceptor Perspective, Cambridge University Press, 2005; d) E. D. Glendening, J. K. Badenhoop, A. E. Reed, J. E. Carpenter, J. A. Bohmann, C. M. Morales, C. R. Landis, F. Weinhold, NBO 6.0, Theoretical Chemistry Institute, University of Wisconsin, Madison, 2013.

[32] A. J. Arduengo, J. C. Calabrese, A. H. Cowley, H. V. R. Dias, J. R. Goerlich, W. J. Marshall, B. Riegel, Inorg. Chem. 1997, 36, 2151-2158.

[33] A. Doddi, M. Weinhart, A. Hinz, D. Bockfeld, J. M. Goicoechea, M. Scheer, M. Tamm, Chem. Commun. 2017, 53, 6069-6072.

[34] T. Krachko, J. C. Slootweg, Eur. J. Inorg. Chem. 2018, 2018, 2734-2754.

[35] A. Doddi, M. Peters, M. Tamm, Chem. Rev. 2019, 119, 6994-7112. 